\title{
TEOR DE ÁGUA E FERTILIDADE DO SOLO COM CAFEEIROS CULTIVADOS EM SISTEMAS AGROFLORESTAIS ${ }^{1}$
}

Yonara Poltronieri Neves ${ }^{2}$, Herminia Emilia Prieto Martinez ${ }^{3}$, Caetano Marciano de Souza ${ }^{3}$ e Paulo Roberto Cecon ${ }^{5}$

\begin{abstract}
RESUMO - Com o objetivo de comparar a umidade e a fertilidade do solo em sistemas de cafeeiro consorciado com níveis baixos de adubação e em cultivo convencional, foram testados os seguintes tratamentos: cafeeiro (Coffea arabica L.) a pleno sol; cafeeiro com fedegoso; cafeeiro com fedegoso e bananeira; cafeeiro com fedegoso, bananeira e ipê-preto, os três últimos com a mesma densidade de plantas consorciadas e todos os tratamentos com o mesmo número de plantas de café. O ensaio foi mantido por 57 meses, e a retenção de água pelo solo e a evolução da fertilidade no período foram avaliados na última estação seca (54 meses). A economia hídrica tem balanço favorável para o cultivo em consórcio no início da estação seca, porém sua manutenção dependerá da exigência hídrica dos componentes do consórcio e do regime hídrico. O cultivo consorciado favoreceu a manutenção do $\mathrm{pH}$ e a redução da saturação por alumínio, muito embora as necessidades de nutrientes dos componentes do consórcio devam ser satisfeitas por meio de entradas externas, para evitar o empobrecimento gradual do solo.
\end{abstract}

Palavras-chave: Conservação da água, consórcio, e saturação por alumínio.

\section{SOIL MOISTURE AND SOIL FERTILITY OF COFFEE IN AGROFORESTRY SYSTEMS}

\begin{abstract}
The aim of this study was to compare the soil moisture and fertility in coffee systems intercropped with trees with low levels of fertilization and in conventional system; the following systems were tested: coffee (Coffea arabica L.) under full light; coffee with Senna macranthera; coffee with Senna macranthera and Musa sp.; coffee with Senna macranthera, Musa sp. and Zeyhera tuberculosa. The last three systems were evaluated with the same density of intercropped plants and all treatments with the same number of coffee plants. The trial was conducted during a 57-month period. A favorable balance for water conservation in the soil was obtained in the intercropped system at the beginning of the dry season. However, the maintenance of this balance will depend on the water demand of the components of the intercropped system and the dry season duration. The intercropped system favored $\mathrm{pH}$ stability and reduction in aluminum saturation, nevertheless the nutrient requirement of the components of the intercropped system should be supplied by means of external inputs, to avoid soil impoverishment.
\end{abstract}

Keywords: Water conservation, intercropping and aluminum saturation.

\section{INTRODUÇÃO}

O uso de árvores associadas com a cultura do cafeeiro é prática comum em países tropicais utilizando, sobretudo, leguminosas. A geração de renda adicional, proveniente das árvores, seja madeira ou frutas, é vantajosa para o agricultor, uma vez que diminui o risco de prejuízos nas épocas de preços críticos do café (MUSCHLER e BONNEMANN, 1997; LYNGBAEKetal., 2001). Ao mesmo tempo, o sistema de cultivo sombreado permite a diminuição dos custos de produção, pelo baixo uso de fertilizantes e agroquímicos (PERFECTO et al., 1996). Abiodiversidade conservada nesses sistemas diminui o efeito do ataque de pragas (SANCHEZ, 2002).

\footnotetext{
${ }^{1}$ Recebido em 17.10.2006 e aceito para publicação em 29.03.2007.

${ }^{2}$ Bolsista do FUNCAFÉ. Departamento de Fitotecnia da Universidade Federal de Viçosa (UFV), 36570-000 Viçosa-MG. Email: <yonarapoltronieri@ hotmail.com>.

${ }^{3}$ Departamento de Fitotecnia da UFV. E-mail: <herminia@ufv.br $>$ e $<$ cmsouza@ufv.br $>$.

${ }^{4}$ Departamento de Informática da UFV. E-mail: <cecon@ dpi.ufv.br>.
} 
O sucesso de um sistema agroflorestal está relacionado à quantidade de nutrientes fornecida pelas podas durante o processo de decomposição, e como esses nutrientes lançados satisfazem as necessidades da colheita (MENDONÇA e STOTT, 2003).

Aranguren et al. (1982) relataram que Inga sp. e Erythrina sp. podem fornecer até $78 \mathrm{~kg} \mathrm{ha}^{-1} \mathrm{ano}^{-1}$ de nitrogênio em associações com cafeeiros. Contudo, os nutrientes trazidos pelo componente arbóreo não têm como destino obrigatório os cafeeiros, podendo ser reaproveitados pelas próprias árvores, dependendo, principalmente, da espécie, da densidade populacional e do manejo das podas.

Os sistemas agroflorestais também podem promover melhorias na eficiência de uso da água (BLACK e ONG, 2000). As condições microclimáticas modificadas provenientes da presença de dois ou mais componentes do sistema que diferem na estrutura da copa e na dinâmica de crescimento podem criar um ambiente atmosférico que aumenta a eficiência do uso da água. Por exemplo, pode haver aumento na umidade relativa e redução na velocidade do vento dentro do dossel, diminuindo a demanda evaporativa (CHIRWA et al., 2007).

Em um sistema agroflorestal, foi registrada para quebra-ventos a redução da evaporação na ordem de 20 a $30 \%$, bem como a diminuição do escoamento superficial em terras inclinadas, com incremento da água infiltrada e maior eficiência no uso da água (YOUNG, 1989; NARAIN et al., 2000).

Alguns autores como Singh et al. (1989), Anderson et al. (1992) e Ong et al. (1992) afirmaram que, no sistema agroflorestal, ocorre competição pelos recursos disponíveis, diminuindo o rendimento e o crescimento dos cultivos perenes ao esgotar a água do solo. No entanto, Jaramillo e Cháves (1999) observaram que os solos dos cafezais sombreados com ingá (Inga sp.) não apresentaram deficiência de água durante os períodos críticos, e nos cafezais a pleno sol ocorreram deficiências severas.

O objetivo deste trabalho foi avaliar a retenção de água e a fertilidade do solo em sistemas de cultivo consorciado e convencional de cafeeiros com níveis baixos de adubação.

\section{MATERIAL E MÉTODOS}

O experimento foi realizado em Viçosa, $\mathrm{MG}$, situada $581 \mathrm{~m}$ de altitude, $20^{\circ} 45^{\prime}$ latitude sul e $42^{\circ} 51^{\prime}$ longitude oeste, no período entre fevereiro de 1995 e novembro de 1999. A temperatura e a precipitação médias anuais, durante o período experimental, foram de $21,6^{\circ} \mathrm{Ce} 1.188,4$ $\mathrm{mm}$, respectivamente.

Os dados de temperatura, precipitação e umidade relativa do ano de 1999, quando foram realizadas as amostragens para avaliação do teor de água do solo, estão apresentados nas Figuras 1 e 2.

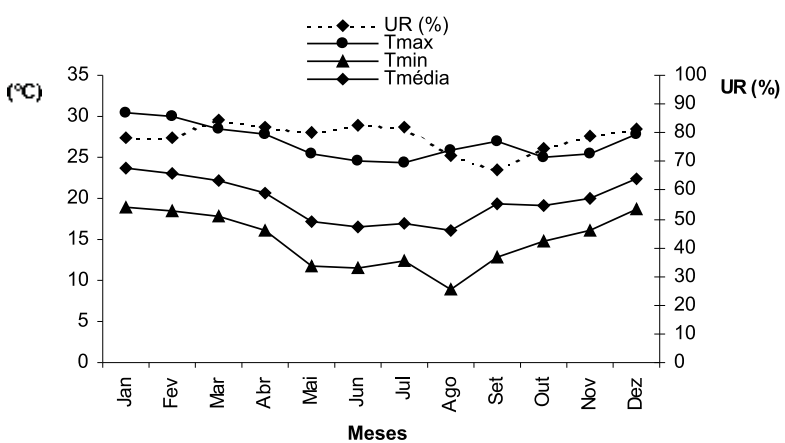

Figura 1 - Temperaturas máxima (Tmax), média (Tmédia) e mínima (Tmin) e umidade relativa do ar, obtidas na Estação Meteorológica de Viçosa, MG, no ano de 1999.

Figure 1-Maximum, medium and minimum temperatures and air relative humidity obtained from Viçosa Meteorological Station, MG, 1999.
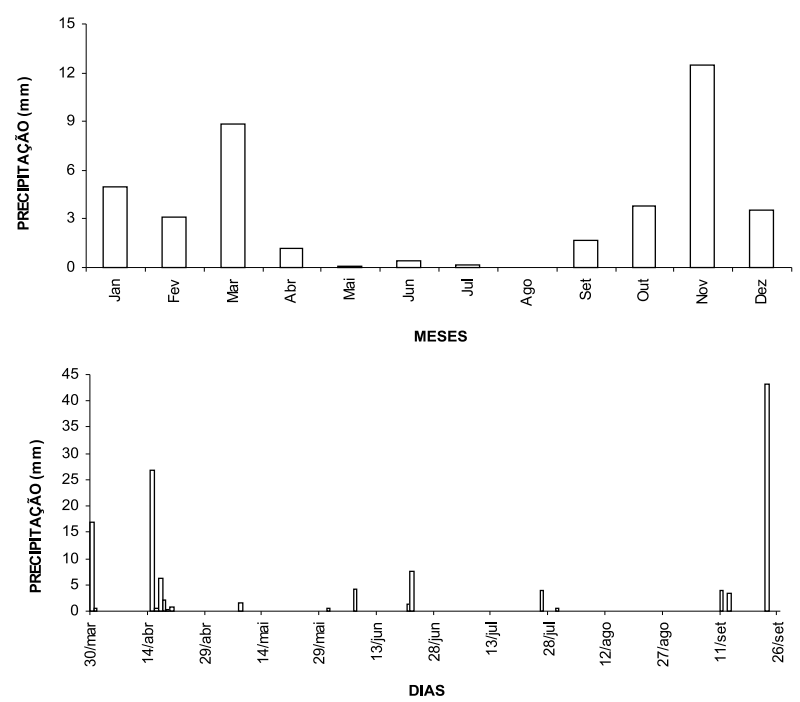

Figura 2-Média mensal da precipitação pluvial diária (mm) (A) e precipitação pluvial diária $(\mathrm{mm})(\mathrm{B})$ do período de amostragempara determinaçãodaumidade do solo, obtidas na Estação Meteorológica de Viçosa, MG.

Figure 2-Monthly mean of daily precipitation $(\mathrm{mm})(\mathrm{A})$ and daily precipitation $(\mathrm{mm})(B)$ during the sampling period, for soil moisture determination, from Viçosa Meteorological Station, MG. 
O solo da área experimental é um Latossolo VermelhoAmarelo distrófico, textura média, com declividade média de $30 \%$ e exposição noroeste, cujas características químicas são apresentadas no Quadro 1.

O experimento foi instalado em delineamento em blocos casualizados com quatro tratamentos e quatro repetições. As parcelas experimentais apresentaram, cada uma, $224 \mathrm{~m}^{2}$ de área total e $96 \mathrm{~m}^{2}$ de área útil. As mudas de cafeeiro e das espécies usadas no consórcio foram dispostas na seguinte forma: cafeeiros em espaçamento $4 \times 2 \mathrm{~m}$ e demais espécies nas entrelinhas do cafeeiro, em espaçamento de 4 x $4 \mathrm{~m}$. Os tratamentos constituíram-se de: cafeeiro (Coffea arabica L) cv. CatuaíVermelho a pleno sol (tratamento 1); cafeeiro com fedegoso (Senna macranthera DC. ex Collad. Irwin et Barneby) (tratamento 2); cafeeiro com fedegoso e bananeira (Musa sp.) (tratamento 3); e cafeeiro com fedegoso, bananeira e ipê-preto (Zeyhera tuberculosa Bur. ex Verlot) (tratamento 4), os três últimos com a mesma densidade de plantas consorciadas (12) e todos os tratamentos com o mesmo número de cafeeiros (28).

Em todas as parcelas onde o cafeeiro se encontrava consorciado foram implantadas espécies de plantas anuais e semiperenes nas entrelinhas, durante o período experimental. Os resíduos culturais foram utilizados como cobertura morta. As espécies implantadas foram: milho (Zea mays L.), feijão-de-porco (Canavalia ensiformis D.C.), feijão-guandu (Cajanus cajan Millsp) e capim-napier (Pennisetum purpureum Schum. cv. Napier). Durante o período experimental foram realizadas capinas no tratamento a pleno sol e ceifa das invasoras nos demais tratamentos, mantendo-se, assim, o manejo usual de cada sistema de produção.

As calagens e as adubações de plantio e de cobertura nos anos agrícolas 1995/1996, 1996/1997, 1997/1998 e 1998/ 1999 seguiram o cronograma do Quadro 2.

A necessidade de calagem foi calculada pelo método do $\mathrm{Al}^{+3} \mathrm{e} \mathrm{Ca}^{+2}+\mathrm{Mg}^{+2}$ trocáveis, através da fórmula $\mathrm{NC}=$ $\mathrm{Al}^{+3}$ x $3+\left[3-\left(\mathrm{Ca}^{+2}+\mathrm{Mg}^{+2}\right)\right]$, conforme CFSEMG (1989). Por considerar-se os tratamentos consorciados menos sujeitos à acidificação gradual do solo, reduziu-se a dose de calcário a eles aplicada para $2 / 3$ da necessidade de calagem calculada. O calcário dolomítico foi aplicado nos anos agrícolas 1994/1995, 1996/1997 e 1998/1999.

Quadro 1 - Análise química do solo no ano de $1995^{1}$

Table 1 - Soil chemical analysis in the year 1995'

\begin{tabular}{|c|c|c|c|c|c|c|c|c|c|c|c|c|}
\hline \multicolumn{13}{|c|}{ Análise Química } \\
\hline Prof. & pH água & $\mathrm{P}$ & K & $\mathrm{Al}$ & $\mathrm{Ca}$ & $\mathrm{Mg}$ & $\mathrm{H}+\mathrm{Al}$ & $\mathrm{SB}$ & CTC Efetiva & CTC Total & $\mathrm{V}$ & $\mathrm{m}$ \\
\hline $\mathrm{cm}$ & & \multicolumn{2}{|c|}{$\mathrm{mg} \mathrm{dm}^{-}$} & \multicolumn{6}{|c|}{$\mathrm{cmol}_{\mathrm{c}} \mathrm{dm}^{-3}$} & & \multicolumn{2}{|c|}{$\%$} \\
\hline $0-20$ & 4,89 & 3,44 & 52,31 & 0,63 & 1,3 & 0,61 & 4,95 & 2,05 & 2,68 & 7,00 & 29,23 & 25,74 \\
\hline
\end{tabular}

( ${ }^{1} \mathrm{pH}$ : 1:2, $5 \mathrm{KCl}$; P e K: Extrator Mehlich 1; Al, Ca e Mg: Extrator $\mathrm{KCl} 1 \mathrm{~mol} / \mathrm{L} ; \mathrm{H}+\mathrm{Al}$ : Extrator Ca(OAc) 0,5 mol/L pH 7,00; SB: Soma de Bases Trocáveis; V: Saturação por Bases; m: Saturação por Alumínio; CTC: Capacidade de Troca Catiônica).

Quadro 2 - Cronograma de adubações e calagens dos anos de 1995 a 1999

Table 2 - Annual lime and fertiliser doses and aplication schedules from 1995 to 1999

\begin{tabular}{lccc}
\hline Ano Agrícola & Tratamento & Adubação (g/cova) & Calagem (g/cova) \\
\hline Instalação & 1 & $00: 40: 72\left(\mathrm{~N}_{2} \mathrm{P}_{2} \mathrm{O}_{5}: \mathrm{K}_{2} \mathrm{O}\right)+20 \mathrm{~L} \mathrm{E.C}{ }^{1 /}$ & $62+15(\mathrm{C}: \mathrm{G})$ \\
& 2,3 e 4 & $00: 14+60: 00\left(\mathrm{~N}: \mathrm{P}_{2} \mathrm{O}_{5}: \mathrm{K}_{2} \mathrm{O}\right)+20 \mathrm{~L}$ E.C. & $41+10(\mathrm{C}: \mathrm{G})$ \\
\hline $1995 / 1996$ & 1 & $24: 6: 24\left(\mathrm{~N}: \mathrm{P}_{2} \mathrm{O}_{5}: \mathrm{K}_{2} \mathrm{O}\right)$ & - \\
& 2,3 e 4 & $8 \mathrm{~L} \mathrm{E.C.}$ & 200 \\
\hline $1996 / 1997$ & 1 & $97: 21: 84\left(\mathrm{~N}: \mathrm{P}_{2} \mathrm{O}_{5}: \mathrm{K}_{2} \mathrm{O}\right)$ & 133 \\
\hline $1997 / 1998$ & 2,3 e 4 & $27: 5: 21\left(\mathrm{~N}: \mathrm{P}_{2} \mathrm{O}_{5}: \mathrm{K}_{2} \mathrm{O}\right)$ & - \\
& 1 & $84: 00: 48\left(\mathrm{~N}: \mathrm{P}_{2} \mathrm{O}_{5}: \mathrm{K}_{2} \mathrm{O}\right)+4 \mathrm{~L} \mathrm{E.G.}{ }^{21}+2,64 \mathrm{~B}$ & - \\
\hline $1998 / 1999$ & 2,3 e 4 & $21: 00: 12\left(\mathrm{~N}: \mathrm{P}_{2} \mathrm{O}_{5}: \mathrm{K}_{2} \mathrm{O}\right)+4 \mathrm{~L}$ E.G. $+0,66 \mathrm{~B}$ & 67 \\
& 1 & $114: 12: 67\left(\mathrm{~N}_{2} \mathrm{P}_{2} \mathrm{O}_{5}: \mathrm{K}_{2} \mathrm{O}\right)$ & 45 \\
\hline
\end{tabular}

( ${ }^{1 /}$ E.C.: Esterco de curral). $\left({ }^{2 /}\right.$ E.G.: Esterco de Galinha). 
As adubações de instalação e de manutenção nos anos agrícolas 1995/1996 e 1996/1997, no tratamento a pleno sol, foram feitas segundo o IBC (1986). Nos tratamentos em consórcio agroflorestal, a adubação mineral de cobertura do cafeeiro iniciou-se no ano agrícola 1996/1997, utilizando-se a quarta parte da adubação recomendada, a fim de encontrar um nível de adubação que satisfizesse nutricionalmente a condição sombreada, haja visto que, nesse caso, possivelmente o requerimento nutricional do cafeeiro sombreado seja menor, em virtude de seu maior estímulo à emissão de gemas vegetativas em detrimento das gemas florais (CANNEL, 1976) e à redução do número de nós produzidos por ramos (CASTILLO e LÓPEZ, 1966).

As adubações nos demais anos agrícolas foram feitas com base na produção estimada (MATIELLO, 1991). A produção estimada no ano agrícola 1997/1998 foi de 1 saca ha-1 em todos os tratamentos, e no ano agrícola 1998/1999 foi de 8 e 2 sacas ha $^{-1}$ no tratamento a pleno sol e nos tratamentos em consórcios agroflorestais, respectivamente. Somente os cafeeiros receberam calagem e adubação.

Considerando que os sistemas consorciados fornecem maiores quantidades de matéria orgânica, favorecendo a solubilização do fósforo e reduzindo a sua fixação por alumínio e ferro, optou-se por utilizar nesses tratamentos fontes de fósforo pouco solúveis em água. Segundo Casida Junior (1959), a solubilização ocorre como resultado da ativação da microflora pela adição de matéria orgânica.

Para a análise do teor de água do solo foram retiradas, nas entrelinhas de plantio do cafeeiro, uma amostra simples por parcela às profundidades de 0 a $5 \mathrm{~cm} ; 5$ a $10 \mathrm{~cm} ; 10$ a $20 \mathrm{~cm}$ e 20 a $40 \mathrm{~cm}$, aos 0,29 , $63,125,131,142,149,156,170$ e 191 dias após a última chuva, ocorrida em 30 de março de 1999. As amostras foram encaminhadas ao Laboratório do Departamento de Física do Solo da UFV e a massa úmida da amostra, mensurada em balança de precisão; posteriormente, essas amostras foram colocadas em estufa a $105^{\circ} \mathrm{C}$ até peso constante. Através da massa seca, foi determinada a porcentagem de água do solo.

A capacidade de campo (CC) e o ponto de murcha permanente (PMP) foram determinados em amostras de terra fina secada ao ar coletadas nas profundidades entre $0-20 \mathrm{~cm}$ e $20-40 \mathrm{~cm} \mathrm{e}$ submetidas às pressões de 0,3 bar (CC) e de 15 bar (PMP), conforme Embrapa (1997).
O experimento, para análise dos dados do teor de água do solo, foi disposto segundo o esquema de parcelas subdivididas, tendo nas parcelas os tratamentos (T1, T2, T3 e T4) e, nas subparcelas, os dias após o início do período $\operatorname{seco}(1,7,18,25$ e 32), que corresponderam às datas de 03, 09, 20 e 27 de agosto e 03 de setembro de 1999, respectivamente. Essas datas, dentre as 10 de coleta, foram escolhidas por representarem o maior período sem chuvas (Figura 2). Os dados foram analisados por meio de análises de variância e de regressão. Os modelos escolhidos para o fator quantitativo foram baseados na significância dos coeficientes de regressão, utilizando-se o teste de " $t$ " em nível de $95 \%$ de confiança, no coeficiente de determinação e no fenômeno em estudo.

Para análise química do solo, no ano de 1995 foram retiradas, ao acaso, três amostras simples para formar uma composta, por bloco. Já nos anos de 1997, 1998 e 1999 foram retiradas, ao acaso, três amostras simples para formar uma composta em cada parcela. Foram retiradas amostras de solo nas profundidades entre $0-5 \mathrm{~cm}, 5-10 \mathrm{~cm}, 10-20 \mathrm{~cm}$ e $20-40 \mathrm{~cm}$.

As variações ocorridas nas características químicas do solo foram avaliadas entre os anos de 1997-1998, 1998-1999 e 1995-1999. Houve necessidade de transformar os dados para se obterem distribuição normal e homogeneidade de variâncias. Esses dados foram submetidos à análise de variância. Quando a relação entre o maior e o menor valor encontrado no quadrado médio do resíduo foi menor ou igual a cinco, procedeuse à análise conjunta. As médias foram comparadas utilizando-se o teste Tukey em nível de $90 \%$ de confiança.

\section{RESULTADOS E DISCUSSÃO}

\subsection{Teor de água do solo}

Com base nos resultados da análise de regressão (Figuras 3 e 4), verificou-se que as camadas superficiais $(0-5 \mathrm{~cm}$ e $5-10 \mathrm{~cm})$ do solo apresentaram menor conteúdo de água do que as camadas subjacentes (10-20 cm e $20-40 \mathrm{~cm}$ ). Tal comportamento se deve ao fato de estas camadas pertencerem à principal zona de absorção de água pelas raízes (IMBACH et al., 1989), além de estarem mais expostas à evaporação, bem como à perda de água por gravidade. Deve-se ressaltar que o teor de água do solo foi menor que no ponto de murcha permanente (Quadro 3) e, mesmo assim, não ocorreu morte de plantas, em virtude de estas retirarem água de maiores profundidades do solo, não analisadas neste trabalho. 

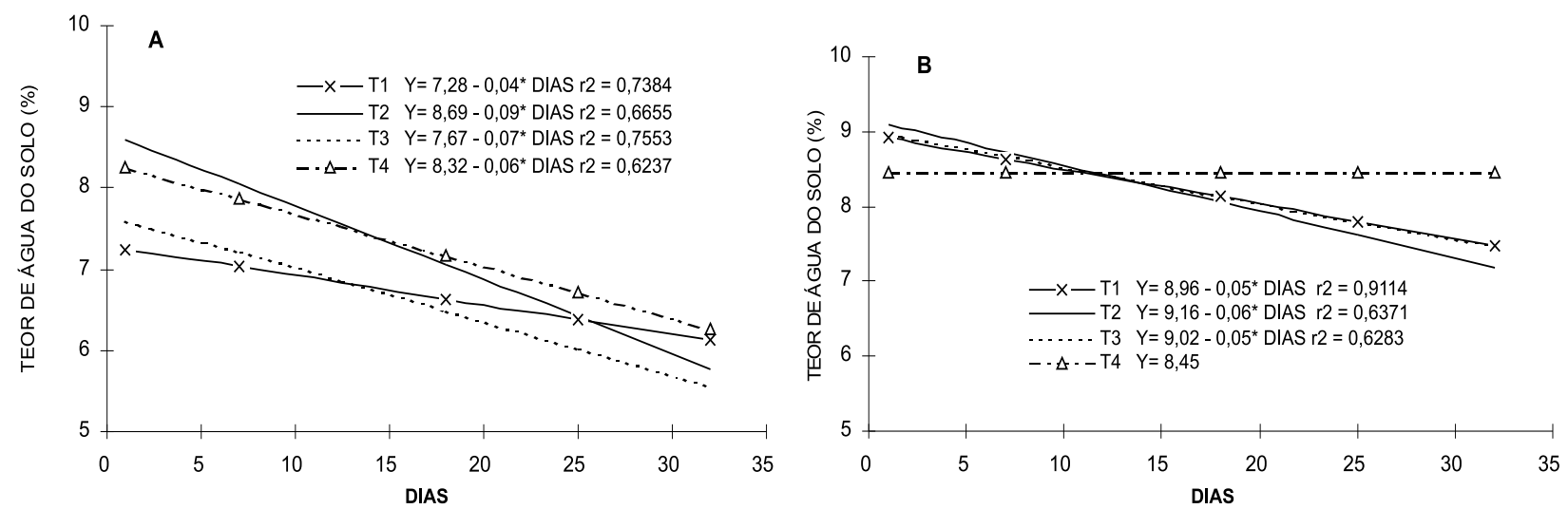

Figura 3 - Estimativa da umidade do solo às profundidades de $0-5 \mathrm{~cm}$ (A) e $5-10 \mathrm{~cm}(\mathrm{~B})$, por tratamento, em função dos dias após o início do período seco (t significativo em nível de $95 \%$ de confiança).

Figure 3 - Soil moisture at $0-5 \mathrm{~cm}(A)$ and $5-10 \mathrm{~cm}(B)$ depths, for each treatment as a function of the duration (days) of the dry period.
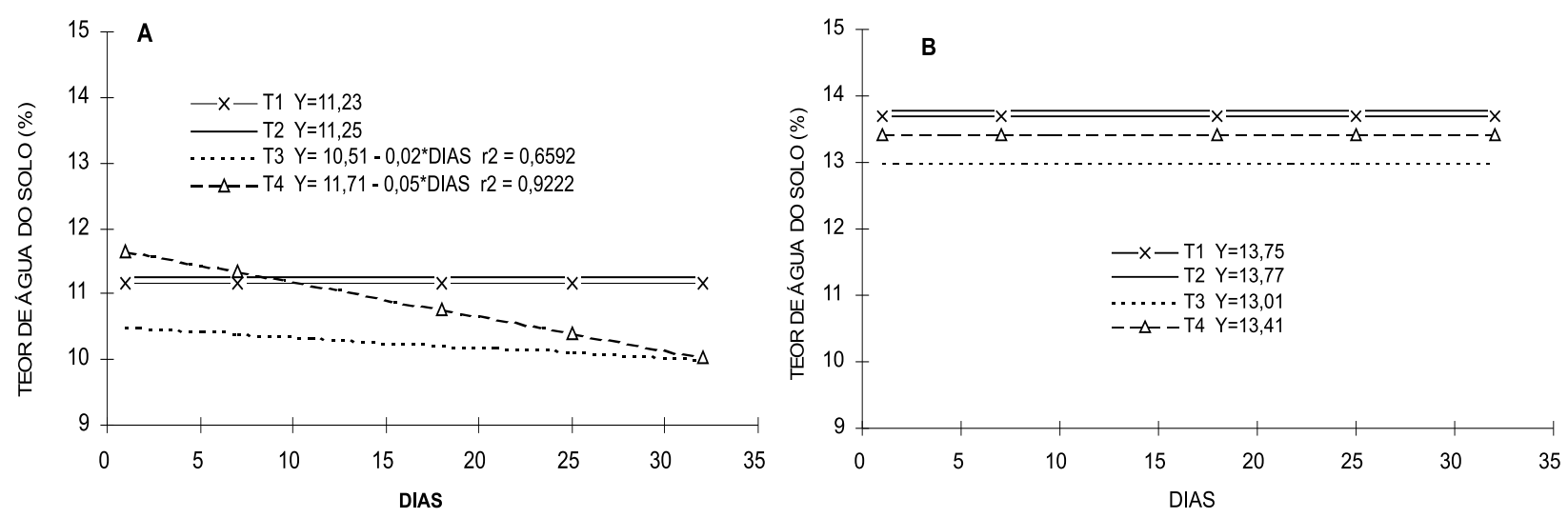

Figura 4 - Estimativa da umidade do solo às profundidades de $10-20 \mathrm{~cm}$ (A) e $20-40 \mathrm{~cm}$ (B), por tratamento, em função dos dias após o início do período seco (* t significativo em nível de $95 \%$ de confiança).

Figure 4-Soil moisture at 10-20 cm (A) and 20-40 cm (B) depths, for each treatment as a function of the duration (days) of the dry period.

Quadro 3 - Valores médios da porcentagem de água do solo nos pontos de capacidade de campo (CC) e de murcha permanente (PMP), em cada tratamento, nas profundidades de 0-20 e $20-40 \mathrm{~cm}$

Table 3 - Soil moisture mean values at the field capacity (CC) and the permanent wilt point (PMP), for each treatment and at $0-20$ and $20-40 \mathrm{~cm}$ depths

\begin{tabular}{|c|c|c|c|c|}
\hline Tratamentos & $\begin{array}{c}\text { Profundidade das } \\
\text { Amostras }\end{array}$ & $\begin{array}{l}\text { Teor de } \\
\text { Água }\end{array}$ & $\begin{array}{c}\mathrm{CC} \\
(0,3 \text { Bar })\end{array}$ & $\begin{array}{c}\text { PMP } \\
(15 \mathrm{Bar})\end{array}$ \\
\hline Cafeeiro (T1) & $0-20 \mathrm{~cm}$ & 8,70 & 22,02 & $\overline{15,40}$ \\
\hline Cafeeiro (T1) & $20-40 \mathrm{~cm}$ & 13,75 & 26,15 & 17,59 \\
\hline Cafeeiro e Fedegoso (T2) & $0-20 \mathrm{~cm}$ & 8,86 & 24,43 & 14,85 \\
\hline Cafeeiro e Fedegoso (T2) & $20-40 \mathrm{~cm}$ & 13,78 & 26,31 & 18,40 \\
\hline Cafeeiro, Fedegoso e Bananeira (T3) & $0-20 \mathrm{~cm}$ & 8,35 & 23,57 & 14,60 \\
\hline Cafeeiro, Fedegoso e Bananeira (T3) & $20-40 \mathrm{~cm}$ & 13,01 & 25,75 & 18,37 \\
\hline Cafeeiro, Fedegoso, Bananeira e Ipê preto (T4) & $0-20 \mathrm{~cm}$ & 8,85 & 22,70 & 14,85 \\
\hline Cafeeiro, Fedegoso, Bananeira e Ipê preto (T4) & $20-40 \mathrm{~cm}$ & 13,42 & 22,19 & 15,08 \\
\hline
\end{tabular}

R. Árvore, Viçosa-MG, v.31, n.4, p.575-588, 2007 
No início do período seco, observou-se que os tratamentos com maior diversidade apresentaram maior teor de água do solo, à profundidade de $0-5 \mathrm{~cm}$, comparativamente ao tratamento a pleno sol (Figura 3A). Isso ocorreu devido à adição de matéria orgânica em decorrência das podas e quedas das folhas das plantas consorciadas. Esse material orgânico não decomposto sobre a superfície do solo, aliado às plantas do consórcio agroflorestal, atuou protegendo-o contra a incidência direta dos raios solares e dos ventos, importantes fatores na perda de água por evaporação. A matéria orgânica e, principalmente, a sua fração húmica também exercem grande influência no armazenamento da água, aumentando a capacidade de infiltração devido às melhorias das condições físicas do horizonte superficial do solo, por exemplo aumentando a granulação e a estruturação e protegendo a superfície contra a formação de crostas impermeáveis (KIEHL, 1985). Os efeitos do material orgânico podem ser visualizados na Figura 3A, em que se verifica que o tratamento a pleno sol iniciou o período seco com menor teor de água, comparativamente aos tratamentos do consórcio agroflorestal.

Ao final do período seco, nas profundidades entre 0 e $5 \mathrm{~cm}$ (Figura 3A) as diferenças quanto ao teor de água no solo entre os tratamentos foram pequenas, apesar de aqueles em consórcio agroflorestal mostrarem maior teor de água no solo no início do período seco. Os consórcios agroflorestais, por terem maior número de plantas, perdem mais água por transpiração, e, como conseqüência, o conteúdo de água do solo nestes tratamentos diminuiu mais rapidamente que no tratamento a pleno sol, como observado na Figura 3A.

Na camada entre 5 e $10 \mathrm{~cm}$ (Figura 3B), no final do período seco a diferença entre os tratamentos quanto ao teor de água no solo também foi pequena. Porém, ao início do período seco, os valores encontrados no teor de água no solo estavam em torno de $9 \%$, ou seja, a perda de água ocorreu de maneira similar entre os tratamentos, nessa camada, excetuando-se o tratamento 4, no qual não houve variações ao longo do período considerado.

Na camada entre 10 e $20 \mathrm{~cm}$ (Figura 4A), os tratamentos 3 e 4 apresentaram decréscimo no teor de água, enquanto os tratamentos 1 e 2 não apresentaram variações ao longo do tempo. Também nessa camada o tratamento com maior número de bananeiras foi o que exibiu menor teor de água no solo.

Na camada entre 20 e $40 \mathrm{~cm}$ (Figura 4B) não houve variação no teor de água no período de tempo considerado, porém os tratamentos 3 e 4 apresentaram menor teor de água que os tratamentos 1 e 2 .

A diferença no teor de água entre os tratamentos estudados foi pequena em todas as profundidades, indicando que, na região e espécies estudadas, a água não seria um fator limitante para o cultivo consorciado do cafeeiro.

\subsection{Fertilidade do solo}

No Quadro 4, encontram-se as diferenças entre os pares de anos referentes às variações médias de $\mathrm{pH}$, saturação por alumínio, potássio $(\mathrm{K})$, cálcio $(\mathrm{Ca})$ e magnésio (Mg) no solo. O sinal negativo que antecede os valores indica que houve aumento no valor das variáveis do solo analisadas em relação ao ano anterior.

\subsection{1. $\mathrm{pH} \mathrm{e} \mathrm{Al}^{+3}$}

Houve gradiente de $\mathrm{pH}$ de $0 \mathrm{~cm}$ a $40 \mathrm{~cm}$ de profundidade (Figura 5), porém não ocorreu efeito dos tratamentos sobre o pH do solo ao longo do tempo, à exceção do período 1997-1998, nas profundidades entre 5 e 10 e 10 e $20 \mathrm{~cm}$, em que o tratamento com maior diversidade de espécies (T4) foi o que obteve maior aumento no pH do solo (Quadro 4).

A saturação por alumínio foi sempre maior no tratamento do cafeeiro a pleno sol, especialmente nas camadas subsuperficiais (Figura 6). Ao longo do tempo, do plantio até o ano de 1999 observou-se que nas camadas entre 0-5 e 5-10 cm a saturação por alumínio, no início e final do período, nos tratamentos com cafeeiro, fedegoso, bananeira e ipê-preto, foi menor que no tratamento cafeeiro a pleno sol (Quadro 4).

Nos tratamentos 1 e 4, a saturação por alumínio, no início do experimento nas camadas entre 0 e 5 e 5 e $10 \mathrm{~cm}$ eram de 8,88 e $29,23 \%$, respectivamente. No final, no tratamento 4 era nula na camada entre 0 e $5 \mathrm{~cm}$ e de $3,95 \%$ na camada entre 5 e $10 \mathrm{~cm}$. No entanto, no tratamento 1 a saturação elevou-se a 13,80 e a $32,10 \%$, nas profundidades de 0 a 5 e de 5 a $10 \mathrm{~cm}$, respectivamente, apesar das maiores quantidades de calcário empregadas. 
Quadro 4 - Variações médias de pH e saturação por alumínio (\%), $\mathrm{K}\left(\mathrm{mg}_{\mathrm{dm}} \mathrm{dm}^{-3}\right)$, $\mathrm{Ca}\left(\mathrm{cmol}_{\mathrm{c}} \mathrm{dm}^{-3}\right)$ e $\mathrm{Mg}\left(\mathrm{cmol}_{\mathrm{c}} \mathrm{dm}^{-3}\right)$ no solo de cafezais a pleno sol e consorciado e seus coeficientes de variação (C.V.)

Table 4-Mean variations and variation coefficients (CV) of pH, aluminum saturation (\%), potassium ( $\left.\left.\mathrm{mg}^{\mathrm{d}} \mathrm{dm}^{-3}\right), \mathrm{calcium}^{(\mathrm{cmol}} \mathrm{dm}^{-3}\right)$ and magnesium contents $\left(\mathrm{cmol}_{c} \mathrm{dm}^{-3}\right)$ of soils with coffee cultivated in single and intercropped systems

\begin{tabular}{|c|c|c|c|c|c|c|c|c|}
\hline \multirow{3}{*}{\multicolumn{2}{|c|}{$\begin{array}{c}\text { Elemento } \\
\text { Anos } \\
\text { Tratamento / Profundidade } \\
\end{array}$}} & \multicolumn{4}{|c|}{$\mathrm{pH}$} & \multicolumn{3}{|c|}{ Saturação por Alumínio } \\
\hline & & \multicolumn{3}{|c|}{$1997-1998^{2}$} & \multirow{2}{*}{$\frac{1997-1998^{1}}{0-5 \mathrm{~cm}}$} & \multicolumn{3}{|c|}{$1995-1999^{1}$} \\
\hline & & $5-10 \mathrm{~cm}$ & \multicolumn{2}{|c|}{$10-20 \mathrm{~cm}$} & & \multicolumn{2}{|l|}{$0-5 \mathrm{~cm}$} & $5-10 \mathrm{~cm}$ \\
\hline \multicolumn{2}{|l|}{ Cafeeiro (T1) } & $0,03(1,41) \mathrm{ab}$ & \multicolumn{2}{|c|}{, $03(1,42) a b$} & $-10,65(5,25) b$ & \multicolumn{2}{|c|}{$-4,93(5,80) b$} & $-2,88(5,98) b$ \\
\hline \multicolumn{2}{|l|}{ Cafeeiro e Fedegoso (T2) } & $0,25(1,50) \mathrm{a}$ & \multicolumn{2}{|c|}{, $23(1,49) \mathrm{ab}$} & $1,50(6,44) \mathrm{a}$ & \multicolumn{2}{|c|}{$7,60(6,90) a b$} & $13,05(7,27) a b$ \\
\hline \multicolumn{2}{|c|}{ Cafeeiro, Fedegoso e Bananeira (T3) } & $-0,15(1,35) a b$ & \multicolumn{2}{|c|}{$0,25(1,50)$ a } & $-2,28(6,14) a b$ & \multicolumn{2}{|c|}{$5,48(6,74) \mathrm{ab}$} & $12,83(7,23) a b$ \\
\hline \multicolumn{2}{|c|}{ Cafeeiro, Fedegoso, Bananeira e Ipê (T4) } & $-0,48(1,23) b$ & \multicolumn{2}{|c|}{$0,30(1,28) \mathrm{b}$} & $0,00(6,32) a b$ & $8,88(6,99)$ & & $25,28(8,07) \mathrm{a}$ \\
\hline C.V $(\%)$ & & 12,44 & 10,8 & & 11,12 & 11,12 & & 12,03 \\
\hline Elemento & & & & Potás & ssio & & & \\
\hline Anos & $1995-1999^{3}$ & $1997-1998^{4}$ & & $55-1999^{3}$ & $1998-1999^{5}$ & $1995-19$ & $99^{3}$ & $1995-1999^{3}$ \\
\hline Tratamento / Profundidade & $0-5 \mathrm{~cm}$ & & $0 \mathrm{~cm}$ & & & $20 \mathrm{~cm}$ & & $20-40 \mathrm{~cm}$ \\
\hline Cafeeiro (T1) & $-29,75(12,70) b$ & $-42,00(11,00) a b$ & -87 & $5(10,32) b$ & $-1,00(9,01) \mathrm{ab}$ & $-42,50(12$ & $2,45) b$ & $-73,00(10,70) c$ \\
\hline Cafeeiro e Fedegoso (T2) & $12,25(14,55) \mathrm{ab}$ & $-25,00(11,79)$ a & $-37,7$ & $(12,72) a b$ & $-15,00(8,33) b$ & $-14,00(13$ & ,62) ab & $-45,50(12,36) b c$ \\
\hline Cafeeiro, Fedegoso e & $35,75(15,33) a b$ & $-26,50(11,71)$ a & $-41,7$ & $(12,43) \mathrm{ab}$ & $11,25(9,62) a b$ & $5,00(14,3$ & 31) ab & $-18,00(13,45) a b$ \\
\hline Bananeira (T3) & & & & & & & & \\
\hline $\begin{array}{l}\text { Cafeeiro, Fedegoso, } \\
\text { Bananeira e Ipê (T4) }\end{array}$ & $78,25(16,66) \mathrm{a}$ & $-65,50(8,79) b$ & $-2,2$ & $(14,03) \mathrm{a}$ & $36,25(10,84)$ a & $23,5(14$, & 95) a & $1,00(14,17) \mathrm{a}$ \\
\hline$\overline{C . V(\%)}$ & 11,57 & 17,08 & & 17,08 & 12,40 & $\overline{12,4}$ & & 9,54 \\
\hline Elemento & & Cálcio & & & & Magnésio & & \\
\hline Anos & $1997-1998^{7}$ & $1998-1999^{6}$ & $-1999^{6}$ & $1998-1999^{6}$ & $1997-1998^{2}$ & $1998-1999^{6}$ & 1998-1 & $1995-1999^{6}$ \\
\hline Tratamento/Profundidade & $10-20 \mathrm{cr}$ & & $10 \mathrm{~cm}$ & & $10 \mathrm{~cm}$ & $10-20 \mathrm{~cm}$ & & $20-40 \mathrm{~cm}$ \\
\hline Cafeeiro(T1) & $0,43(1,85) a b$ & $0,15(1,05) b$ & $1,00) \mathrm{b}$ & $0,10(1,05) \mathrm{ab}$ & $0,00(1,41) \mathrm{a}$ & $0,00(1,00) b$ & $0,13(1$, & $0,23(1,10) \mathrm{a}$ \\
\hline Cafeeiro e Fedegoso (T2) & $0,58(1,89) \mathrm{a}$ & $0,36(1,15) \mathrm{b}$ & $1,10) \mathrm{b}$ & $0,00(0,99) \mathrm{b}$ & $-0,03(1,40)$ a & $0,03(1,01) b$ & $0,03(1$ & $-0,03(0,98) b$ \\
\hline Cafeeiro, Fedegoso e & $0,50(1,87) \mathrm{ab}$ & $0,90(1,36) \mathrm{ab}$ & $1,48) \mathrm{a}$ & $0,53(1,22) \mathrm{a}$ & $0,03(1,42) \mathrm{a}$ & $0,25(1,11) \mathrm{ab}$ & $0,35(1$ & $0,23(1,10) \mathrm{a}$ \\
\hline Bananeira(T3) & & & & & & & & \\
\hline Cafeeiro, Fedegoso, & $-0,55(1,47) b$ & $1,65(1,59)$ a & $1,26) a b$ & $0,48(1,21) \mathrm{a}$ & $-0,53(1,18) b$ & $0,65(1,27) \mathrm{a}$ & $0,23(1$, & ) ab $\quad 0,10(1,04) a b$ \\
\hline Bananeira e Ipê (T4) & & & & & & & & \\
\hline C.V (\%) & 17,61 & 17,61 & 2,18 & 12,40 & 12,09 & 12,09 & 6,4 & 6,43 \\
\hline
\end{tabular}

Dentro de cada elemento na mesma época e profundidade as médias seguidas de pelo menos uma mesma letra na coluna não diferem entre si, no nível de $90 \%$ de confiança, pelo teste de Tukey.

() Dados transformados em Raiz Quadrada (X+40); ${ }^{2}$ ( ) Dados transformados em Raiz Quadrada (X+2); ${ }^{3}$ ( ) Dados transformados em Raiz Quadrada (X+200); ${ }^{4}$ ( ) Dados

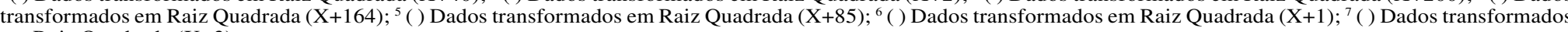
em Raiz Quadrada (X+3) 

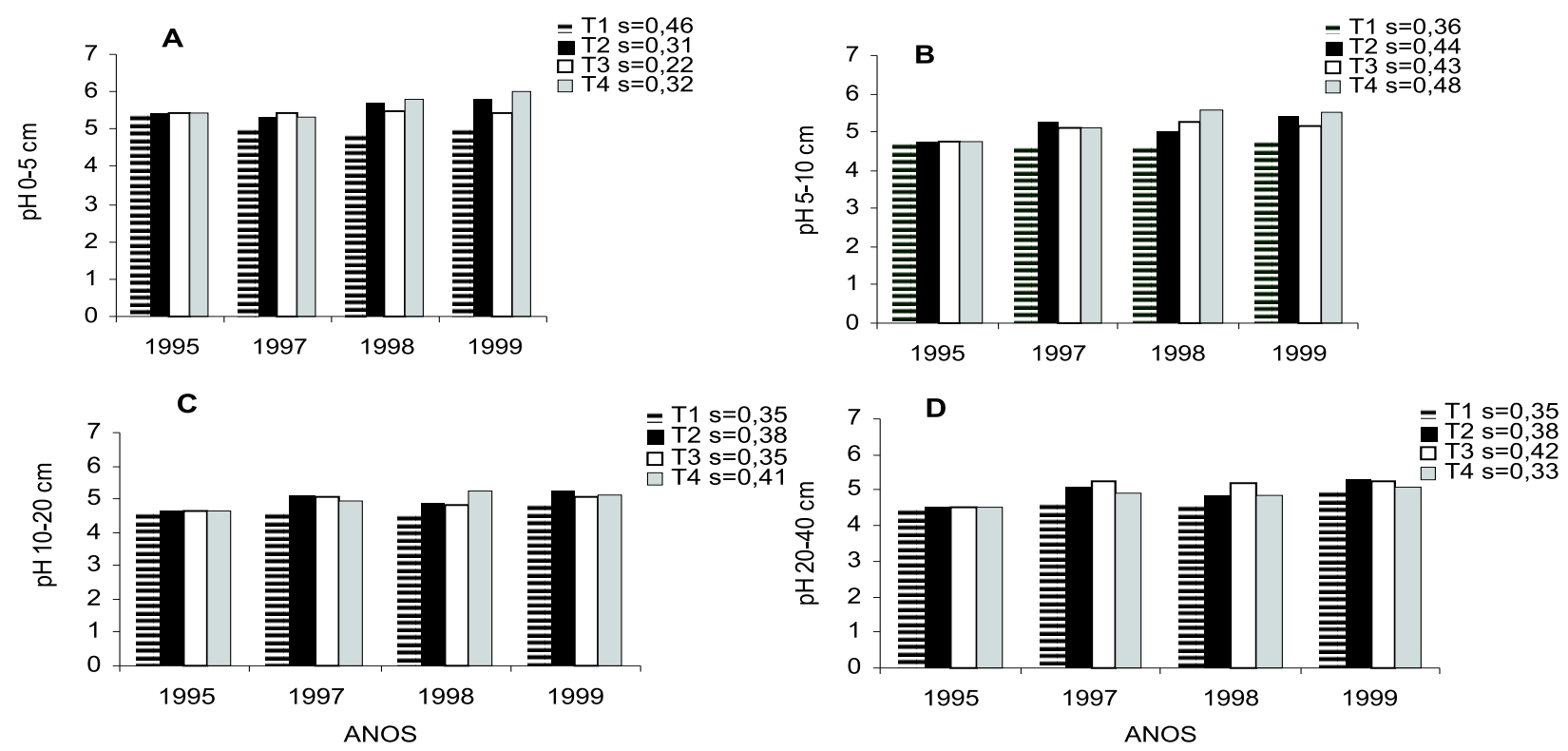

Figura 5 - Valores médios do pH do solo por tratamento, nas profundidades de 0-5 (A), 5-10 (B), 10-20 (C) e 20-40 (D) cm, nos anos de 1995, 1997, 1998 e 1999, e os respectivos valores de desvio padrão (s).

Figure 5-Soil pH mean values and standard error (s) for each treatment, at O- 5 (A), 5-10 (B), 10-20 (C) and 20-40 cm (D) depths, in the years of 1995, 1997, 1998 and 1999.
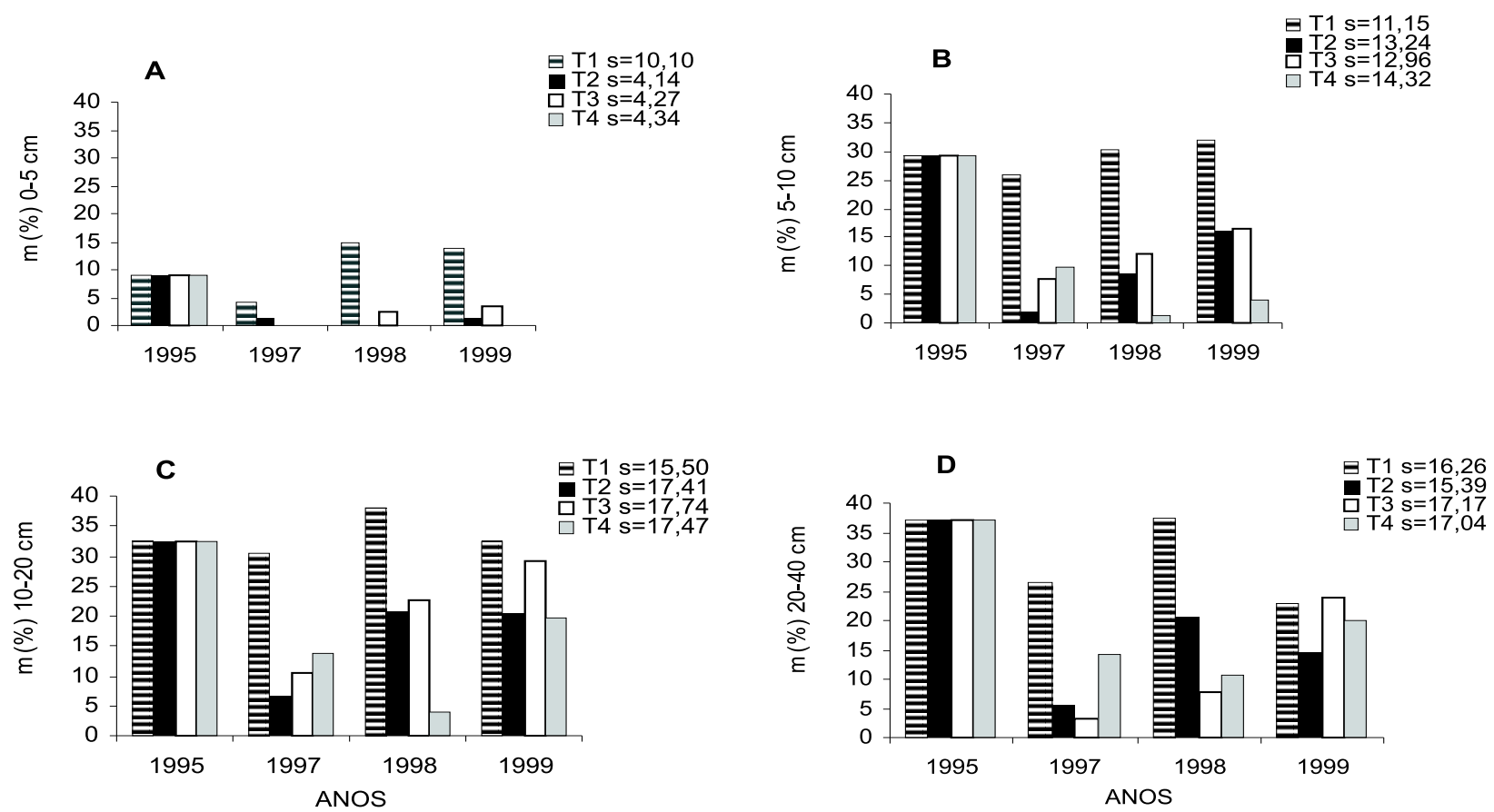

Figura 6 - Valores médios da saturação por alumínio (\%) por tratamento, às profundidades de 0-5 (A), 5-10 (B), 10-20 (C) e 20-40 (D) cm, nos anos de 1995, 1997, 1998 e 1999, e os respectivos valores de desvio-padrão (s).

Figure 6-Aluminum saturation mean values (\%) and standard error $(\mathrm{s})$ for each treatment, at $0-5(\mathrm{~A}), 5-10(\mathrm{~B}), 10$ $20(C)$ and 20-40 cm (D) depths, in the years of 1995, 1997, 1998 and 1999.

R. Árvore, Viçosa-MG, v.31, n.4, p.575-588, 2007 
Considerando que os tratamentos em consórcio agroflorestal receberam $2 / 3$ da quantidade recomendada de calcário para a correção da acidez do solo, é provável que nesses tratamentos possam ter ocorrido reações de complexação do alumínio com compostos orgânicos, como por processos de adsorção superficial ou quelatação, presentes em maiores proporções nos tratamentos em consórcio agroflorestal. Freitas e Mendonça (2000), estudando a dinâmica da matéria orgânica nessa mesma área, observaram que o teor de carbono orgânico na camada de $5-25 \mathrm{~cm}$ foi maior nos tratamentos consorciados e, dentre os tratamentos em consórcio, o que apresentou maior teor foi o tratamento 4, evidenciando-se que não somente a quantidade, mas também a qualidade do material orgânico acrescentado ao solo exerce influência sobre os níveis de carbono.

Os resultados deste trabalho podem estar relacionados à maior quantidade de adubo nitrogenado recebido pelo tratamento a pleno sol, já que há liberação de íons de hidrogênio como subproduto da conversão bacteriana de nitrogênio amoniacal em nitrogênio nítrico, no processo de nitrificação, o que contribuiu para a acidificação dos solos.

\subsubsection{Potássio}

Os teores de $\mathrm{K}$ no início do experimento estavam abaixo do considerado adequado para o cafeeiro, de acordo com Malavolta (1997), aumentando com o decorrer do tempo. No tratamento a pleno sol (T1), o K aumentou até o ano de 1998 em todas as camadas e mais acentuadamente na superfície, diminuindo em 1999 devido à remoção de K pela colheita (Figura 7).

Ao avaliar os teores de $\mathrm{K}$ ao longo do tempo, observou-se que, apesar de o tratamento 1 ter recebido maior aporte de K, não houve efeito entre tratamentos, nas camadas entre 0-5 cm em 1997-1998 e 1998-1999 e à profundidade de 5-10 cm nos anos 1998-1999. Isso pode estar relacionado à maior perda por lixiviação e, ou, erosão e também ao aporte do material de cobertura em decomposição sobre o solo, nos tratamentos em consórcio agroflorestal, já que o K é liberado rapidamente do material vegetal em decomposição para o solo, e a adição do nutriente, via adubo, foi pequena.
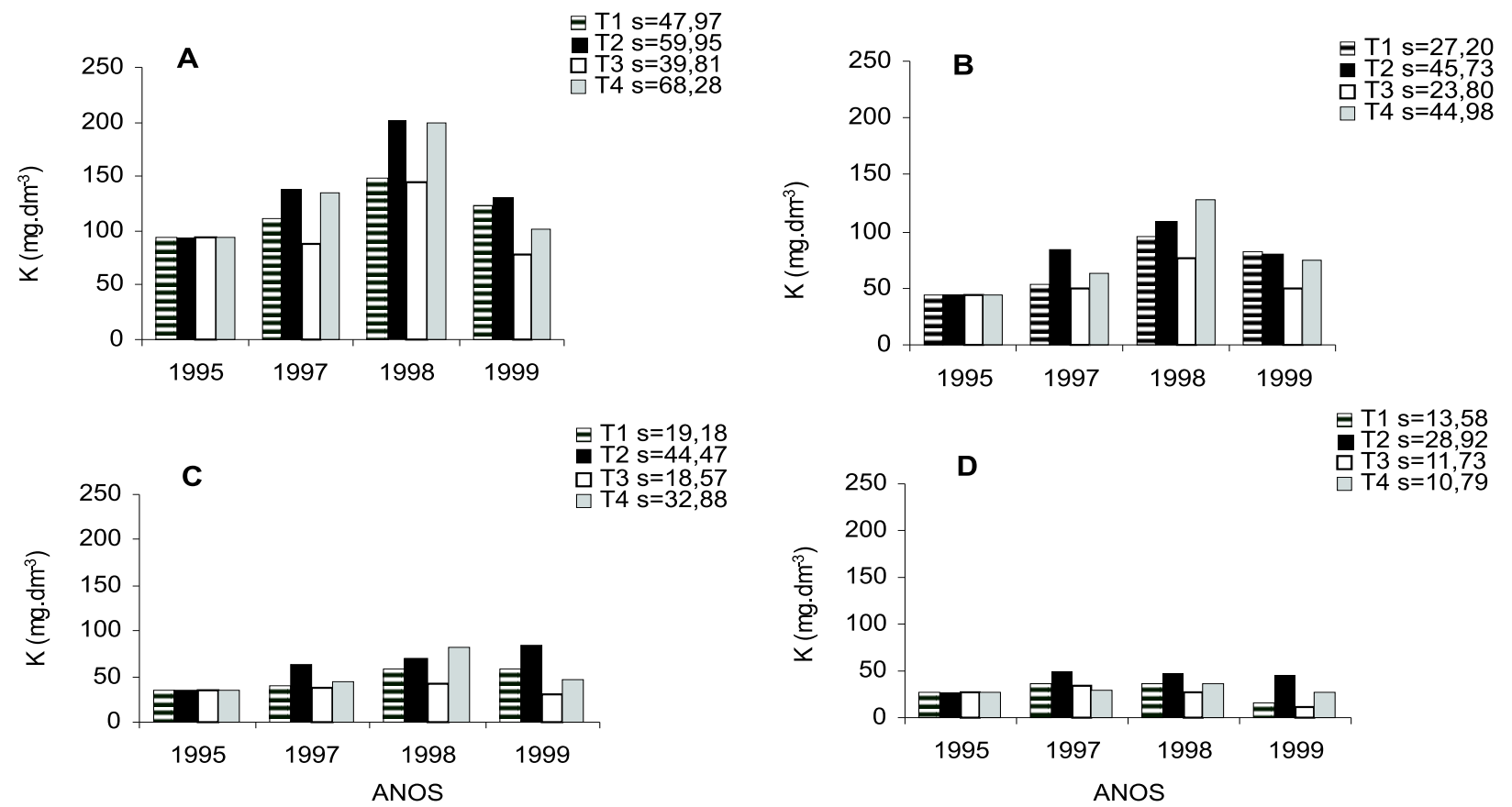

Figura 7 - Valores médios do $\mathrm{K}\left(\mathrm{mg} \mathrm{dm}^{-3}\right)$ por tratamento, às profundidades de 0-5 (A), 5-10 (B), 10-20 (C) e 20-40 (D) cm, nos anos de 1995, 1997, 1998 e 1999, e os respectivos valores de desvio-padrão (s).

Figure 7 - Potassium content mean values $\left(\mathrm{mg} \mathrm{dm}^{-3}\right)$ and standard error $(\mathrm{s})$ for each treatment, at from $0-5$ (A), $5-10$ (B), 10-20 (C) and 20-40cm (D) depths, in the years of 1995, 1997, 1998 and 1999. 
Analisando as diferenças nos teores de K do solo entre 1995-1999 (Quadro 4), observou-se, em todas as profundidades, que o tratamento a pleno sol apresentou elevação do teor de K comparativamente ao tratamento 4. A adubação de manutenção no T1 (Quadro 2) e, ou, a presença de bananeiras, que são exigentes em K, no $\mathrm{T} 4$, podem ter sido responsáveis pelo fato.

Os tratamentos 2 e 3 apresentaram-se em posição intermediária entre os tratamentos 1 e 4 até $20 \mathrm{~cm}$ de profundidade, entre 1995-1999, sem diferir deles (Quadro 4). Tal fato se deve à menor quantidade de adubo aplicado (Quadro 2), comparativamente ao tratamento 1 e ao menor rendimento de grãos, de acordo com Neves (2007), comparativamente ao tratamento 4 , o que possibilitou menor exportação de $\mathrm{K}$ do solo.

Nesse mesmo período (1995-1999), na profundidade de $20-40 \mathrm{~cm}$ o tratamento a pleno sol foi superior aos tratamentos 3 e 4, e o tratamento 2 foi superior ao 4, quanto ao teor de K. É provável que esse resultado seja decorrência da presença da bananeira nos tratamentos 3 e 4. Essa cultura apresenta elevada demanda por K, reduzindo o teor desse nutriente no solo. Tal efeito, aparentemente, começou a manifestar-se entre os anos de 1998-1999 na camada entre 10 e $20 \mathrm{~cm}$ de profundidade.

Nos anos de 1997-1998, na camada de 5-10 cm o teor de K no tratamento 4 foi superior aos dos tratamentos 2 e 3, não diferindo do tratamento a pleno sol (Quadro 4). Nessa mesma camada, foi observado por Freitas e Mendonça (2000) maior teor de carbono orgânico no tratamento 4. A matéria orgânica aumenta a capacidade de troca catiônica do solo, diminuindo as perdas de bases por lixiviação, de acordo com Malavolta (1993). É possível, então, que essa tenha sido a causa do incremento de $\mathrm{K}$ do solo do tratamento 4. Tal comportamento não persistiu no ano seguinte (19981999), devido à extração pelas culturas, sem que houvesse a restituição devida.

\subsubsection{Cálcio e Magnésio}

No início do experimento, os teores de Ca do solo eram inferiores ao considerado adequado para o cafeeiro, segundo Malavolta (1997). Apesar de terem sido realizadas calagens ao longo do período de cultivo, valores entre 3 e $4 \mathrm{cmol}_{c} \mathrm{dm}^{-3}$ de Ca não foram alcançados. Observouse que os tratamentos em consórcio agroflorestal, mesmo recebendo $2 / 3$ da calagem recomendada, mantiveram maiores teores de Ca em superfície e subsuperfície, como verificado no tratamento 2 , ou semelhantes ao tratamento a pleno sol (Figura 8). Já os teores de Mg no solo na camada entre $0-5 \mathrm{~cm}$ de profundidade estão dentro do nível adequado para a cultura, conforme Malavolta (1997), na faixa entre $0,6-1,0 \mathrm{cmol}_{\mathrm{c}} \cdot \mathrm{dm}^{-3}$. Nas demais profundidades, os teores de $\mathrm{Mg}$ estão próximos do recomendado, de acordo com esse mesmo autor (Figura 9).

Não houve efeito significativo de tratamento, quanto ao teor de Ca do solo no intervalo compreendido entre $1997-1998$ e nas profundidades de 0 a $5 \mathrm{~cm}$; de 5 a $10 \mathrm{~cm}$ e de 20 a $40 \mathrm{~cm}$, nos anos de 1995-1999, em todas as profundidades e naquelas de $0-5$ e de $5-10 \mathrm{~cm}$ no período 1998-1999. Também não houve efeito dos tratamentos sobre teor de $\mathrm{Mg}$ no solo na profundidade entre 0 e 5 $\mathrm{cm}$, nos intervalos entre os anos analisados, mesmo esses tratamentos recebendo $2 / 3$ da quantidade de calcário aplicada no tratamento a pleno sol. Assim como o Ca, esses resultados podem estar relacionados à capacidade da matéria orgânica em aumentar a capacidade de troca catiônica, diminuindo a lixiviação desse nutriente no solo, conforme Kiehl (1979). Franco (2002), trabalhando em diversos sistemas agroflorestais, verificou que as perdas de nutrientes por erosão foram menores que nos sistemas a pleno sol, principalmente para $\mathrm{Ca}$ e $\mathrm{Mg}$, encontrando em média, para o Ca, perdas de $92,1 \mathrm{~g} \mathrm{ha}^{-1} \mathrm{ano}^{-1} \mathrm{e} 1.865,5$ $\mathrm{g} \mathrm{ha}^{-1} \mathrm{ano}^{-1}$ nos sistemas agroflorestais e naqueles a pleno sol, respectivamente, e para o $\mathrm{Mg}$, perdas de $17,9 \mathrm{~g} \mathrm{ha}^{-1} \mathrm{ano}^{-1}$ e $625,3 \mathrm{~g} \mathrm{ha}^{-1} \mathrm{ano}^{-1}$, nos sistemas agroflorestais e nos a pleno sol, respectivamente. $\mathrm{Na}$ mesma área experimental em que foi realizado este trabalho, o referido autor encontrou perda por erosão de 14.508,2 $\mathrm{g} \mathrm{ha}^{-1} \mathrm{ano}^{-1}$ de Ca no tratamento a pleno sol.

Na camada entre 10-20 cm no período 1998-1999, o tratamento a pleno sol e o tratamento cafeeiro e fedegoso apresentaram menores reduções no teor de Ca que o tratamento em que o cafeeiro esteve consorciado com fedegoso, bananeira e ipê-preto (Quadro 4). Na camada entre $20-40 \mathrm{~cm}$, os tratamentos 1 e 2 foram superiores ao tratamento cafeeiro, fedegoso e bananeira, quanto ao teor de Ca no solo (Quadro 4). No período 19981999 , nas camadas entre $5-10 \mathrm{~cm}, 10-20 \mathrm{~cm}$ e $20-40 \mathrm{~cm}$ e, em 1995-1999, na camada entre 20 e $40 \mathrm{~cm}$, os tratamentos 3 e 4 apresentaram, para o Ca e $\mathrm{Mg}$, maior redução no solo (Quadro 4). É possível que essa diferença seja devida à menor quantidade de fertilizantes aplicada (Quadro 2). No par de anos 1995-1999, na camada entre 20 e $40 \mathrm{~cm}$ o tratamento a pleno sol também apresentou diminuição no teor de $\mathrm{Mg}$ no solo, possivelmente devido à maior produção de café neste tratamento, de acordo com Neves (2007). 

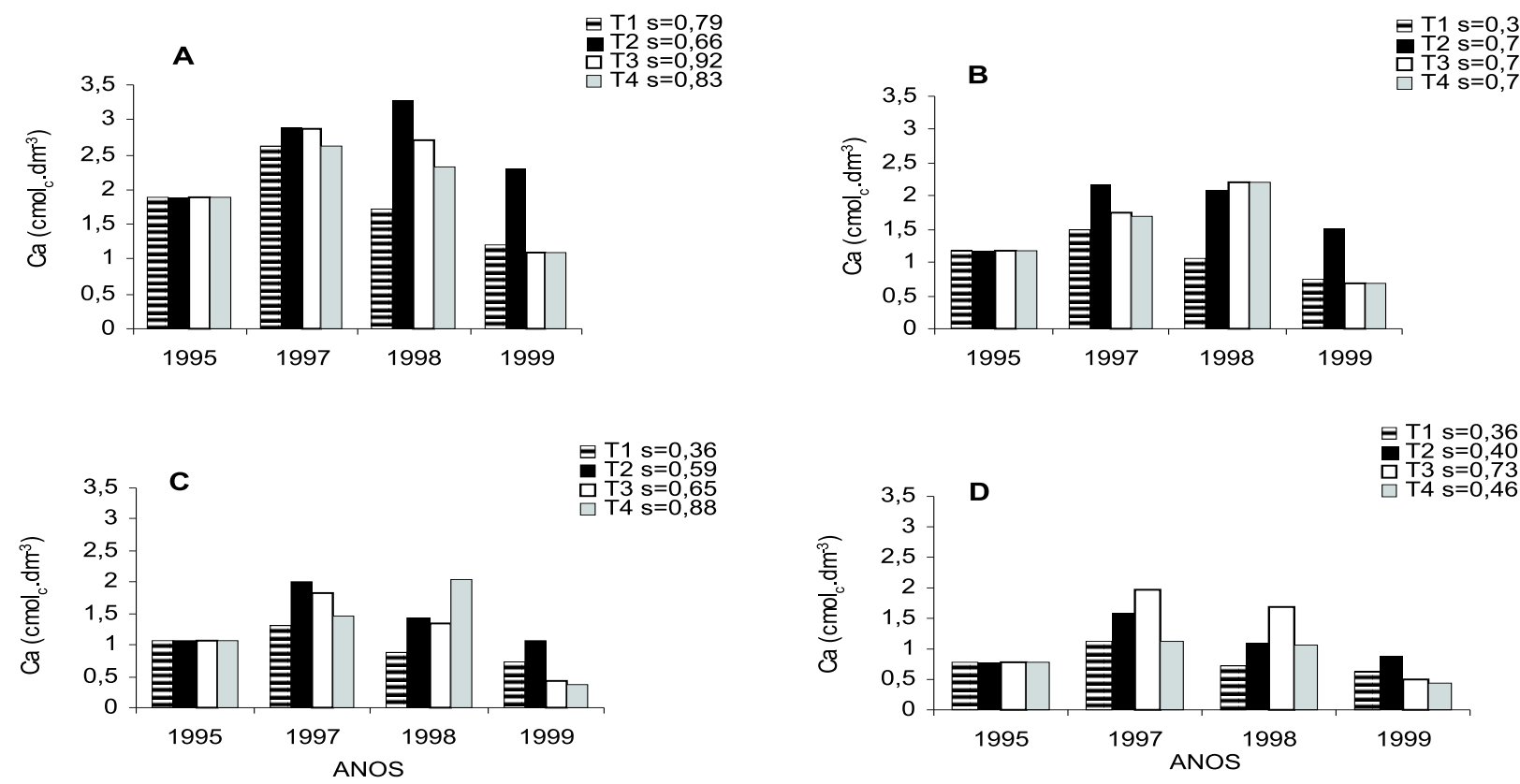

Figura 8 - Valores médios do $\mathrm{Ca}\left(\mathrm{cmol}_{\mathrm{c}} \cdot \mathrm{dm}^{-3}\right)$ por tratamento, às profundidades de 0-5 (A), 5-10 (B), 10-20 (C) e 20-40 (D) cm, nos anos de 1995, 1997, 1998 e 1999, e os respectivos valores de desvio-padrão (s).

Figure8 - Calcium content mean values $\left(\mathrm{cmol}_{c d m^{-3}}\right)$ and standard error (s) for each treatment, at from 0- 5 (A), 5- 10 (B), 10-20 (C) and 20-40cm (D) depths, in the years of 1995, 1997, 1998 and 1999.
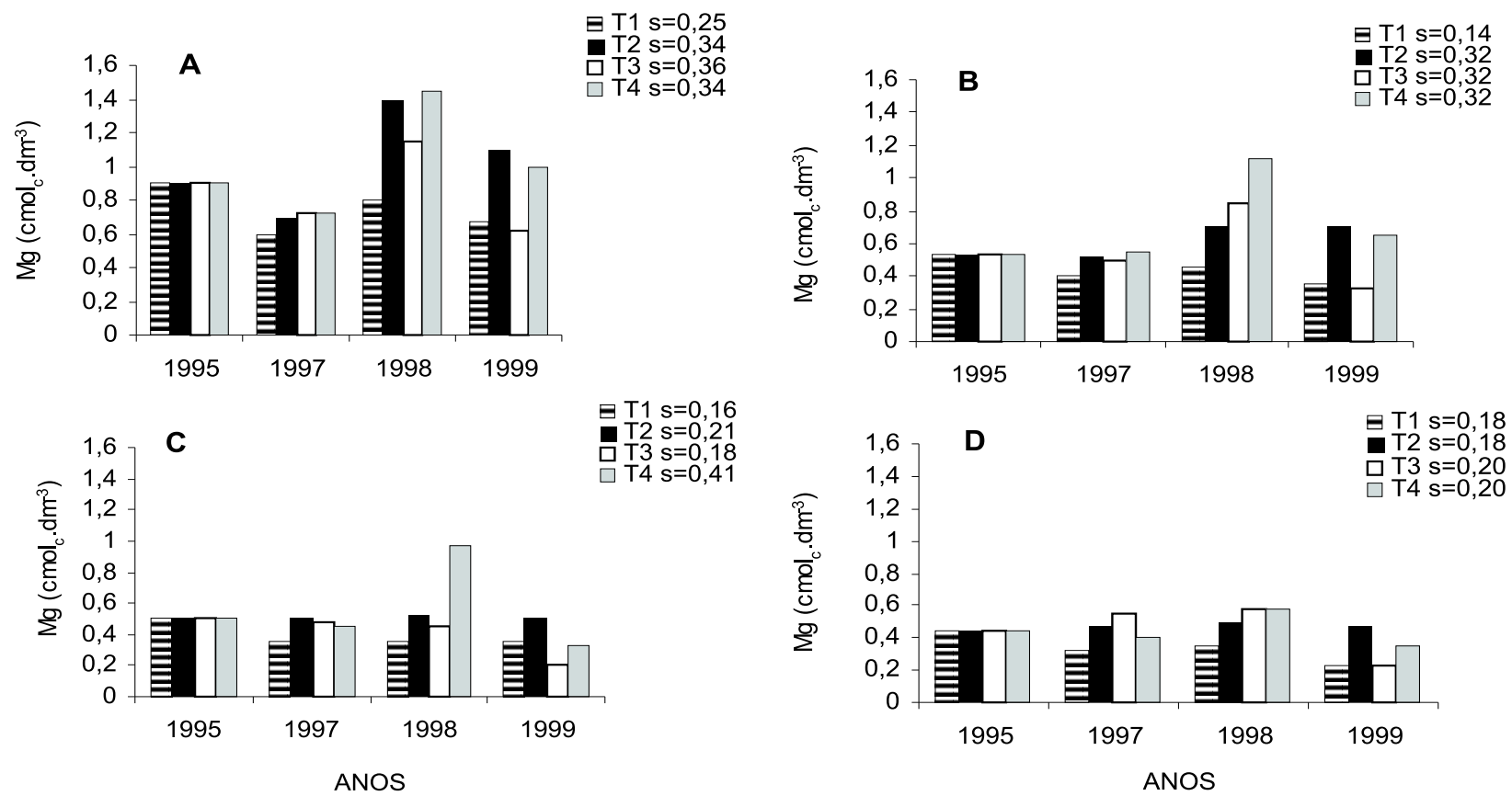

Figura 9 - Valores médios do $\mathrm{Mg}\left(\mathrm{cmol}_{\mathrm{c}} \cdot \mathrm{dm}^{-3}\right)$ por tratamento, às profundidades de 0-5 (A), 5-10 (B), 10-20 (C) e 2040 (D) cm, nos anos de 1995, 1997, 1998 e 1999, e os respectivos valores de desvio-padrão (s).

Figure 9 - Magnesium content mean values $\left(\mathrm{cmol}_{c . d m}^{-3}\right)$ and standard error $(s)$ for each treatment, at from 0- 5 (A), 5 $10(B), 10-20(C)$ and 20-40cm (D) depths, in the years of 1995, 1997, 1998 and 1999. 
Nos anos 1997-1998, a camada entre $10-20 \mathrm{~cm}$, no tratamento 4 , foi superior ao tratamento 2 , quanto ao teor de Ca no solo (Quadro 4). No mesmo período e na mesma profundidade, observou-se que o teor de Mg no tratamento 4 também foi superior e, neste caso, aos demais tratamentos (Quadro 4). O tratamento 4 foi o que obteve maior nível de matéria orgânica, e esta aumenta a capacidade de troca cationnica do solo, diminuindo as perdas de bases por lixiviação. É possível que esta tenha sido a causa do maior incremento do Ca no solo do tratamento 4. Tal comportamento não persistiu no ano seguinte (1998-1999), devido à extração pelas culturas, sem que houvesse a devida restituição.

\subsubsection{Fósforo}

Em todos os tratamentos e em todas as profundidades, observou-se que a concentração de fósforo no solo aumentou até o ano de 1997, decrescendo a seguir (Figura 10). No tratamento a pleno sol, os teores foram sempre inferiores a $10 \mathrm{mg} \mathrm{dm}^{-3}$, tido como limite inferior da faixa adequada para a cultura, segundo Malavolta (1997). Nos tratamentos em consórcio agroflorestal, na camada entre 0 e $5 \mathrm{~cm}$ os teores foram superiores a $10 \mathrm{mg} . \mathrm{dm}^{-3}$ até o ano de 1999 e também na camada entre 5 e $10 \mathrm{~cm}$ até o ano de 1998 (Figura 10). Tal fato pode ser atribuído ao emprego de fosfato natural e termofosfato por ocasião da implantação do experimento, nos tratamentos em consórcio agroflorestal. A solubilização paulatina desse material permitiu manter concentrações mais elevadas de fósforo no solo, por um período de três anos. Maior crescimento e produção, bem como maior perda por erosão no tratamento a pleno sol, também devem estar associados às diferenças observadas entre os tratamentos, principalmente na camada superficial.

Deve-se também considerar que o extrator utilizado (Mehlich 1), em virtude da característica de reação ácida, extrai maiores quantidades de fósforo de solos que receberam fosfato natural e termofosfato.

Quanto à evolução dos teores de fósforo ao longo do tempo não houve efeito de tratamentos sobre o teor de fósforo no solo em todos os intervalos de anos e em todas as profundidades pesquisadas.
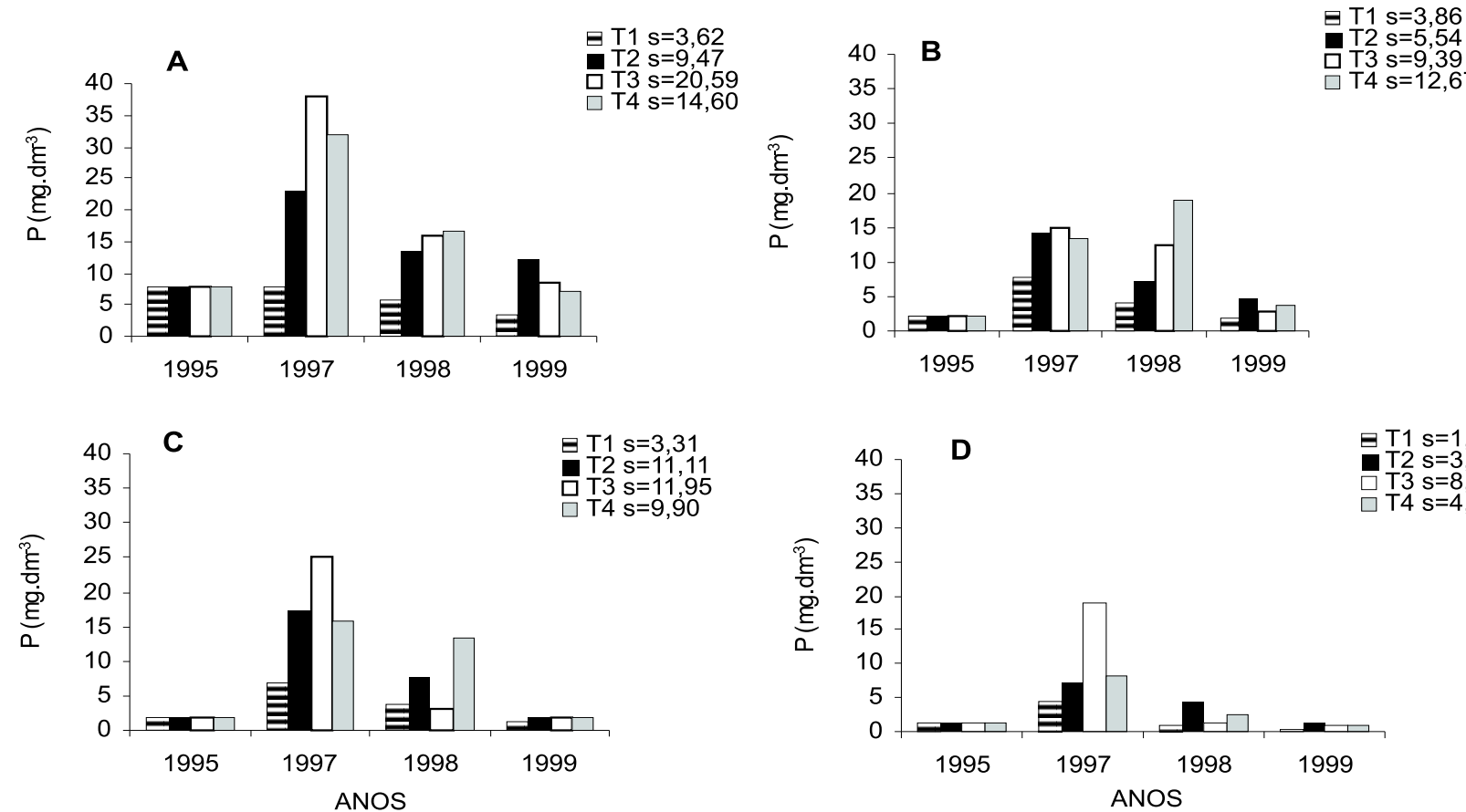

Figura 10 - Valores médios de fósforo $\left(\mathrm{mg}_{\mathrm{dm}} \mathrm{dm}^{-3}\right)$ por tratamento, às profundidades de 0-5 (A), 5-10 (B), 10-20 (C) e 2040 (D) cm, nos anos de 1995, 1997, 1998 e 1999, e os respectivos valores de desvio-padrão (s).

Figure 10 - Phosphorus content mean values $\left(\mathrm{mg}_{\mathrm{dm}} \mathrm{dm}^{-3}\right)$ and standard error $(\mathrm{s})$ for each treatment, at from $0-5$ (A), 5 10 (B), 10-20 (C) and 20-40cm (D) depths, in the years of 1995, 1997, 1998 and 1999.

R. Árvore, Viçosa-MG, v.31, n.4, p.575-588, 2007 


\section{CONCLUSÕES}

De acordo com os dados deste trabalho e nas condições de Viçosa, MG, pode-se concluir que:

* A economia hídrica tem balanço favorável no cultivo em consórcio no início da estação seca, porém a manutenção desse balanço dependerá da exigência hídrica dos componentes do consórcio e da duração do período seco.

* O cultivo consorciado favorece a manutenção do pH e a redução da saturação por alumínio, muito embora as necessidades de nutrientes dos componentes do consórcio devam ser satisfeitas por meio de entradas externas, para evitar o empobrecimento gradual do solo.

\section{REFERÊNCIAS}

ANDERSON, J. L.; BINGHAM, G. E.; HILL, R. W. Effects of permanent cover crop competition on sour cherry tree evapotranspiration, growth and productivity. Acta Horticulture, v.13, p.135-142, 1992.

ARANGUREN, J.; ESCALANTE, G.; HERRERA, R. Nitrogen cycle of tropical perennial crops under shade trees. Plant and Soil, v.67, p.247-258, 1982.

BLACK, C. R.; ONG, C. K. Utilization of light and water in tropical agriculture. Agriculture Forest Meteorology, v.104, p.25-47, 2000.

CANNELL, M. G. R. Crop physiological aspects of coffee bean yield: a review. Kenya Coffee, v.41, n.484, p.245-253, 1976.

CASIDA JUNIOR, L. E. Phosphatase-activity of some common soil fungi. Soil Science, v.87, p.305-310, 1959.

CASTILLO, Z. J.; LÓPEZ, R. A. Nota sobre el efecto de la intensidad de la luz en la floracion del cafeto. Cenicafé, v.17, p.51-60, 1966.

COMISSÃO DE FERTILIDADE DO SOLO DO ESTADO DE MINAS GERAIS - CFSEMG.

Recomendações para o uso de corretivos e fertilizantes em Minas Gerais; $4^{\circ}$ aproximação. Lavras: 1989. 176p.
CHIRWA, P. W. et al. Soil water dynamics in cropping systems containing Gliricidia sepium, pipeonpea and maize in southern Malawi. Agroforest Systems, v.69, p.29-43, 2007.

\section{EMPRESA BRASILEIRA DE PESQUISA} AGROPECUÁRIA - EMBRAPA. Manual de métodos de análises de solo. 2.ed. Rio de Janeiro: Centro Nacional de Pesquisa de Solos, 1997. 212p.

FRANCO, F. S. et al. Quantificação de erosão em sistemas agroflorestais e convencionais na zona da mata de minas gerais. Revista Árvore, v.26, n.6, p.751-760, 2002.

FREITAS, H. R.; MENDONÇA, E. S. Dinâmica da matéria orgânica em sistemas agroflorestais: caracterização da matéria orgânica do solo. In: REUNIÃO BRASILEIRA DE MANEJO E CONSERVAÇÃO DO SOLO E DA ÁGUA, 13., 2000, Anais... Ilhéus: CEPLAC, 2000. p.271-272.

IMBACH, A. C. et al. Sistemas agroforestales de café (Coffea arabica) con Laurel (Cordia alliodora) y café con Poró (Erythrina poeppigiana) en Turrialba, Costa Rica: VI. balances hídricos e ingreso con lluvias y lixiviación de elementos nutritivos.Turrialba, v.39, p.400-414, 1989.

INSTITUTO BRASILEIRO DO CAFÉ. - IBC. Cultura de café no Brasil: pequeno manual de recomendações. Rio de Janeiro: 1986. 214p.

JARAMILLO, R. A.; CHÁVES, C. B. Aspectos hidrológicos en un bosque y en plantaciones de café (Coffea arabica L.) al sol y bajo sombra. Cenicafé, v.50, p.97-105, 1999.

KIEHL, E. J. Manual de edafologia. São Paulo: Agronômica Ceres, 1979. 264p.

KIEHL, E. J. Fertilizantes orgânicos. São Paulo: Agronômica Ceres, 1985. 492p.

LYNGBAEK,A. E.; MUSCHLER, R. G; SINCLAIR, F. L. Productivity and profitability of multistrata organic versus conventional coffee farms in Costa Rica. Agroforestry Systems, v.53, n.2, p.205-213, 2001.

MALAVOLTA, E. Nutrição mineral e adubação do cafeeiro. São Paulo: Agronômica Ceres, 1993. 210p.

R. Árvore, Viçosa-MG, v.31, n.4, p.575-588, 2007 
MALAVOLTA, E.; VITTI, G. C.; OLIVEIRA, S. A. Avaliação do estado nutricional das plantas; princípios e aplicações. 2.ed. Piracicaba: Potafos, 1997. 319p.

MATIELlo, J. B. O café: do cultivo ao consumo. São Paulo: Globo, 1991. 320p.

MENDONÇA, E. S.; STOTT, D. E. Characteristics and decomposition rates of pruning residues from a shaded coffee system in Southeastern Brazil.

Agroforestry Systems, v.57, p.117-125, 2003.

MUSCHLER, R. G.; BONNEMANN, A. Potentials and limitations of agroforestry for changind landuse in the tropics: experiences from Central America. Forest Ecology and

Management, v.91, p.61-73, 1997.

NARAIN, P. et al. Water balance and water efficiency of different land uses in western Himalayan valley region. Agriculture Forest Meteorology, v.37, n.3, p.225-240, 1998.

Disponível em: <http://www.sciencedirect.com>. Acesso em: 29 setembro 2000.
NEVES, Y. P. et al. Crescimento e produção do cafeeiro em sistema agroflorestal. Revista de Biologia e Ciências da Terra. 2007. (no prelo).

ONG, C. K.; RAO, M. R.; MATHUVA, M.

Competition for resources above and below the ground. Agroforestry Today, v.4, p.4-5, 1992.

PERFECTO, I.; RICE, R. A.; GREENBERG, R. Shade Coffee: A disappearing refuge for Biodiversity. BioScience, v.46, n.8, p.598-608, 1996.

SANCHEZ; P. A. Soil fertility and hunger in África. Science, v.295, n.5562, p.2019-2020, 2002.

SINGH, R. P.; ONG, C. K.; SAHARAN, N. Above and below ground interactions in alley-cropping in semi-arid India. Agroforestry Systems, v.9, p.259-274, 1989.

YOUNG, A. Agroforestry takes root in Ethiopia. Agroforestry Today, v.1, p.13-16, 1989. 